\title{
Ética profesional desde la perspectiva sociológica y filosófica
}

\section{Professional Ethics from a Sociological and Philosophical Perspective}

\section{Ética profissional sob uma perspectiva sociológica e filosófica}

\section{Guadalupe Ibarra Rosales}

Universidad Nacional Autónoma de México, Instituto de Investigaciones sobre la Universidad y la Educación, México

irge@unam.mx https://orcid.org/0000-0002-2180-357X

\section{Resumen}

Este texto constituye un análisis crítico de la visión de la ética profesional elaborada por la perspectiva funcionalista de la sociología de las profesiones. La metodología de este análisis comprendió los siguientes aspectos: $a$ ) identificar y desarrollar las tesis y los argumentos principales sobre la ética profesional elaborados por la visión funcionalista de la sociología de las profesiones; $b$ ) examinar estas tesis y sus argumentos con base en los planteamientos de la postura filosófica de la ética profesional, así como desde el enfoque crítico de la sociología de las profesiones, y c) presentar y desarrollar la contribución que hace la perspectiva funcionalista al establecer a la ética profesional como un componente propio de las profesiones modernas. Asimismo, mostrar que esta visión resulta corta y estrecha para comprender que la ética profesional es más que un rasgo o característica de las profesiones, dado que en la actualidad se concibe que aquella es la que dota de sentido a estas. Dentro de los resultados, el análisis crítico da cuenta de que la visión de la ética profesional elaborada por el enfoque funcionalista está determinada por la concepción de las profesiones propia de esta corriente de la sociología. Pero, aunque esta visión tiene limitaciones, establece que la ética profesional es inherente a las profesiones modernas. Mientras que la postura crítica de 


\section{Revista Iberoamericana \\ de las Ciencias Sociales y \\ Humanísticas}

ISSN: $2395-7972$

la sociología de las profesiones devela que, tanto la concepción de una como de la otra, son conceptos sociohistóricos que evolucionan y se modifican, delimitados en gran medida por el contexto económico, social, político y cultural del momento histórico. Por su parte, la perspectiva filosófica de la ética profesional muestra aspectos y dimensiones que no han tomado en cuenta las diferentes corrientes teóricas de la sociología y ofrece un horizonte teórico para comprender y analizar a las profesiones modernas en el marco filosófico.

Palabras clave: códigos éticos, ética profesional, profesionalización, profesiones, sociología de las profesiones.

\section{Abstract}

This text constitutes a critical analysis of the vision of professional ethics elaborated by the functionalist perspective of the sociology of professions. The methodology of this analysis included the following aspects: $a$ ) to identify and develop the thesis and main arguments on professional ethics elaborated by the functionalist vision of the sociology of professions; $b$ ) to examine these theses and their arguments based on the approaches of the philosophical position of professional ethics, as well as the critical approach of the sociology of the professions; and $c$ ) to present and develop the contribution made by the functionalist perspective of the professions by establishing professional ethics as a component of modern professions. Likewise, to show that this vision is short and narrow to understand that professional ethics is more than a trait or characteristic of professions, given that it is currently conceived that such ethics is what gives meaning to modern professions. The critical analysis shows that the vision of professional ethics elaborated by the functionalist approach is determined by the conception of the professions of this current of the sociology of the professions. But, although this vision has limitations, it establishes that professional ethics is inherent in modern professions. While the critical position of the sociology of the professions reveals that, both the conception of the professions and that of professional ethics, are socio-historical concepts that evolve and are modified, largely defined by the economic, social, political and cultural historical moment. For its part, the philosophical perspective of professional ethics shows its aspects and dimensions that have not considered into account the different theoretical currents of the sociology of the professions and offers a theoretical horizon to understand and analyze modern professions in the philosophical framework. 


\section{Revista Iberoamericana \\ de las Ciencias Sociales y \\ Humanísticas}

Keywords: ethical codes, professional ethics, professionalization, professions, sociology of professions.

\section{Resumo}

Este texto constitui uma análise crítica da visão da ética profissional elaborada pela perspectiva funcionalista da sociologia das profissões. A metodologia desta análise incluiu os seguintes aspectos: $a$ ) identificar e desenvolver a tese e principais argumentos sobre ética profissional elaborados pela visão funcionalista da sociologia das profissões; $b$ ) examinar essas teses e seus argumentos com base nas abordagens da posição filosófica da ética profissional, bem como na abordagem crítica da sociologia das profissões; $c$ ) apresentar e desenvolver a contribuição da perspectiva funcionalista das profissões por estabelecer a ética profissional como um componente das profissões modernas. Da mesma forma, mostrar que essa visão é curta e estreita para entender que a ética profissional é mais do que uma característica ou característica das profissões, uma vez que atualmente é concebido que essa ética é o que dá sentido às profissões modernas. A análise crítica mostra que a visão da ética profissional elaborada pela abordagem funcionalista é determinada pela concepção das profissões dessa corrente da sociologia das profissões. Mas, embora essa visão tenha limitações, ela estabelece que a ética profissional é inerente às profissões modernas. Enquanto a posição crítica da sociologia das profissões revela que, tanto a concepção das profissões quanto a ética profissional, são conceitos sócio-históricos que evoluem e são modificados, em grande parte definidos pelos aspectos econômico, social, político e cultural. Por sua vez, a perspectiva filosófica da ética profissional mostra seus aspectos e dimensões que não levaram em conta as diferentes correntes teóricas da sociologia das profissões e oferece um horizonte teórico para entender e analisar as profissões modernas no quadro filosófico.

Palavras-chave: códigos éticos, ética profissional, profissionalização, profissões, sociologia das profissões.

Fecha Recepción: Mayo 2019

Fecha Aceptación: Diciembre 2019 


\section{Revista Iberoamericana \\ de las Ciencias Sociales y \\ Humanísticas}

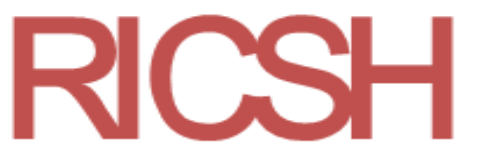

ISSN: $2395-7972$

\section{Introducción}

La temática de la ética profesional y su vinculación con las profesiones modernas ha sido abordada tanto por la sociología de las profesiones como por la perspectiva filosófica de la ética profesional. En el ámbito de la sociología, el eje de la reflexión ha girado en torno a las profesiones modernas como sujetos y grupos que forman parte de la estructura del mercado de trabajo, así como su inserción en el sistema social y participación en el ámbito de poder de la sociedad contemporánea. En esta reflexión, la ética profesional no ha sido el centro de análisis y se ha planteado como un componente o atributo de las profesiones.

En la perspectiva filosófica, el núcleo de análisis ha sido la ética profesional con miras a comprender y cuestionar la práctica de las profesiones modernas en la actualidad. En el enfoque de la sociología, la ética profesional es un atributo más de las profesiones modernas. Para la postura filosófica, existen y se desarrollan gracias a la ética profesional:

La ética profesional no es un añadido a la profesión, sino algo intrínseco a la misma, que la define, la dota de sentido y justifica su existencia y su valor. Sin ética profesional no habría profesión y no a la inversa (Feito, 2009, p. 129).

Así, la sociología de las profesiones se encuentra en el polo que comprende y explica el surgimiento y realización de las profesiones por las características y atributos que las distinguen. En tanto que la perspectiva filosófica de la ética profesional se ubica en el polo que antepone la ética profesional como la esencia de las profesiones modernas. Por esto, considera que esta ética es la base y el sustento que permitió su aparición y progreso en la sociedad contemporánea, debido a que dota de sentido o razón de ser a las profesiones. El análisis crítico que se expone en este texto recupera las formulaciones teóricas elaboradas por la sociología de las profesiones sobre la ética profesional, entendida como atributo de las profesiones, pues posibilita comprender la evolución y los avances que tuvo esta en el siglo XX. Y se recurre al punto de vista filosófico para identificar las restricciones y estrechez de la visión funcionalista y así mostrar el valor y la importancia que tiene la ética para el desarrollo de las profesiones en la sociedad contemporánea. Asimismo, esta visión filosófica se ofrece como línea y posibilidad que permite impulsar y mejorar a la ética profesional en las profesiones modernas actuales. 


\section{Revista Iberoamericana \\ de las Ciencias Sociales y \\ Humanísticas}

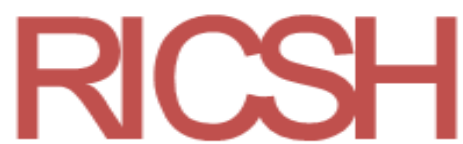

ISSN: $2395-7972$

En este marco, se recuperan como antecedentes de este análisis crítico trabajos e investigaciones elaborados por ambos campos del conocimiento. En el enfoque de la sociología de las profesiones se distingue la investigación de Finkel (2015), que constituye su tesis doctoral, donde expone y desarrolla de manera particular la ética profesional. En un apartado específico, dedicado al estudio del pensamiento de Durkheim, analiza la propuesta de este sociólogo, quien cree que las profesiones pueden ser agentes morales capaces de ayudar a terminar con la anomia y el individualismo para contribuir a lograr la cohesión social y moral de la sociedad de su época. Asimismo, Finkel (2015) recupera la ética profesional al analizar la ética del profesionalismo. En esta misma línea, Aguayo (2003, 2006, 2007, 2008) ha realizado diversas investigaciones sobre las profesiones modernas en las que trata de manera amplia la temática de la ética profesional. Si bien esta autora ha centrado sus estudios en los planteamientos de Max Weber, también analiza la visión funcionalista de las profesiones y la postura crítica de la sociología de las profesiones.

En el campo de la perspectiva filosófica de la ética profesional sobresalen los trabajos teóricos de Hortal $(1993,2002)$, quien analiza la concepción funcionalista de las profesiones modernas y realiza una crítica radical a la visión de la ética profesional que encierra esta vertiente de la sociología. La crítica realizada por este autor se centra en especial en la concepción de la ética profesional como códigos éticos.

En el presente estudio crítico, se analizó la visión de la ética profesional planteada por Carr Saunders y Wilson (1933), Wilensky (citado en Dettmer, 2009) y Moore (citado en Machado, 1991), que son autores clásicos y representativos de la corriente funcionalista de la sociología de las profesiones. Como ya se señaló anteriormente, la metodología de este estudio fue el análisis crítico, y los referentes teóricos en los que se fundamentó son la perspectiva filosófica de la ética profesional (Cortina, 2000, 2006, 2009; Hortal, 1993, 2000; López de la Osa, 1994) y el enfoque crítico de la sociología de las profesiones (Freidson, 2003; Larson, 1989). Las formulaciones teóricas de esos autores permitieron lograr los objetivos de este estudio: a) exponer las contribuciones (alcances) realizadas por la perspectiva funcionalista de las profesiones para entender a la ética profesional como atributo de las profesiones modernas, y b) explicar las limitaciones que tiene esta concepción funcionalista de la ética profesional para comprender y dar cuenta de la relevancia que tiene en la sociedad actual. 


\section{Revista Iberoamericana \\ de las Ciencias Sociales y \\ Humanísticas}

ISSN: $2395-7972$

La ética profesional es un tema significativo no solo en términos teóricos, sino también para la sociedad. Debido a que contribuye en gran medida a que las profesiones modernas cumplan con la función social que les corresponde, esto es, proporcionar el bien y el servicio que requiere la sociedad para su sobrevivencia y desarrollo. En este sentido, para toda sociedad es imperativo contar con profesiones capaces de satisfacer sus necesidades vitales (Cortina, 2000, 2006). Sin embargo, en las últimas dos décadas, la ética profesional ha adquirido especial importancia. En primer lugar, porque los servicios que proporcionan los profesionistas han sido cuestionados de manera seria por los mismos usuarios de estos, debido a que en algunas profesiones modernas prevalecen valores, hábitos y prácticas poco éticas que inciden en la atención que prestan. Por ejemplo, anteponer sus intereses económicos por encima de las necesidades del usuario o realizar su práctica profesional regida por las normas de la burocracia. En algunos casos extremos, se ha comprobado la negligencia en la prestación del servicio con consecuencias graves tanto para los usuarios como para la sociedad en su conjunto. Esto ha empujado a que los usuarios de los servicios profesionales levanten la voz y exijan más a menudo calidad y que realmente respondan a sus necesidades y problemáticas (Martínez, 2006). En segundo término, los servicios que proporcionan un buen número de profesiones constituyen la vía o el medio para concretar los derechos humanos en una sociedad, tal y como la salud, la educación, la vivienda y el trabajo. Lo anterior siempre y cuando estas profesiones desarrollen una práctica profesional ética (Ibarra, 2015). Todo ello sitúa a la ética profesional como el horizonte donde las profesiones pueden recuperar su razón de ser en la sociedad contemporánea, así como afianzar el reconocimiento y la legitimidad que les ha otorgado una sociedad.

El análisis crítico que se presenta en este texto comprende dos apartados. En el primero, se abordó la concepción de la ética profesional como una ética del servicio social elaborada por Carr-Saunders y Wilson (1933). En el segundo, se desarrolló la visión de la ética profesional como códigos éticos formulada por Wilensky (1964), cuyo examen se realizó en el marco del modelo de profesionalización propuesto por este autor. A su vez, este apartado comprende las subsecciones siguientes: la profesión de tiempo completo, profesiones y universidad, profesiones y asociaciones profesionales, profesiones y Estado, profesiones y códigos éticos. 


\section{Revista Iberoamericana \\ de las Ciencias Sociales y \\ Humanísticas}

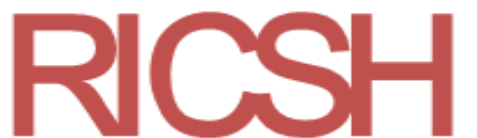

ISSN: $2395-7972$

\section{Ética profesional como ética del servicio profesional}

El estudio de las profesiones modernas por la sociología de las profesiones inicia en los albores del siglo XX con la obra de Carr-Saunders y Wilson (1933). Este siglo estuvo marcado por las condiciones sociales y económicas que experimentaba la sociedad derivadas del acelerado proceso de industrialización enfocado en impulsar y consolidar al capitalismo como modelo económico. Este proceso trajo consigo cambios en la división del trabajo al presentar una creciente especialización: el mercado de trabajo requirió personal altamente calificado y especializado, lo que incentivó el desarrollo de las profesiones modernas. Asimismo, estuvo acompañado de la progresiva urbanización, que forjó nuevos segmentos sociales — incluyendo otro tipo de clase media — de tal forma que la sociedad capitalista en su conjunto presentaba necesidades novedosas y diferentes, al igual que problemáticas diversas, producto de estos cambios radicales que requerían ser resueltas. En este contexto, el Estado nación se situó como la forma de organización política clave y, a la larga, posibilitó este proceso de transformación económica y social de esta sociedad calificada como moderna.

Los cambios en el ámbito moral que presentaba dicha sociedad moderna son significativos para la comprensión de la visión de la ética profesional que predominó en el modelo ideal de las profesiones, elaborado por la concepción funcionalista de la sociología de las profesiones. La sociedad industrial desterró del ámbito moral las ideas religiosas o sobrenaturales con las que se regían las sociedades precapitalistas y antepuso un nuevo tipo de ética totalmente terrenal y concreta, denominada ética del capitalismo, la cual se distinguía por ser "una ética que asociaba el esfuerzo económico a la virtud moral y el éxito a la virtud recompensada" (Hartwell, 1986, p. 9).

El centro de esa ética es la afirmación del individualismo, porque desde la perspectiva del capitalismo solo el individuo libre y autónomo es capaz de alcanzar el logro económico poniendo en juego su empeño, voluntad y determinación. De ahí que el esfuerzo mostrado en la realización de una actividad económica se conciba como una virtud moral. Los valores que acompañan al individualismo son la libertad, la igualdad y la autonomía.

En este contexto histórico, Carr-Saunders y Wilson (1933) realizaron una investigación histórica de un conjunto de profesiones de Inglaterra y, con base en esta, elaboraron una definición básica de las profesiones modernas, que engloba un conjunto de atributos propios que las distinguen. Para estos autores ingleses "quizá pueda definirse una 


\section{Revista Iberoamericana \\ de las Ciencias Sociales y \\ Humanísticas}

ISSN: 2395 - 7972

profesión como una tarea basada en el estudio intelectual especializado y el adiestramiento, cuyo fin es proporcionar servicio o asesoramiento experimentado a los demás en virtud de un honorario definido o un salario" (Carr-Saunders y Wilson, 1939, citados en Tenti, 1989, p. 22).

Con base en esta definición, las características de las profesiones modernas son: a) se comprenden como tareas o funciones que se realizan en la sociedad; $b$ ) estas tareas se desarrollan sustentadas en el conocimiento científico y en habilidades obtenidas a través de una formación educativa especializada; $c$ ) tienen como fin o propósito prestar un servicio a quienes carecen de estos conocimientos y habilidades, y d) se obtiene una remuneración económica por el servicio proporcionado. Este conjunto de atributos ha quedado como inherente a las profesiones modernas y son vigentes en la actualidad.

Para la sociología de las profesiones, esta concepción se enfoca en establecer las diferencias entre los oficios y las profesiones, centrando esta distinción en el conocimiento científico especializado que domina el profesionista y en la formación científica y técnica adquirida, ya que los oficios, puesto que carecen de estos elementos, realizan actividades menos complejas. Es importante señalar que esta visión recupera la prestación de un servicio como el atributo sustantivo de las profesiones, pero en el posterior desarrollo de la perspectiva funcionalista se le otorgará más peso al conocimiento experto avalado por una larga formación universitaria; de hecho, será uno los estandartes de los grupos profesionales para buscar el monopolio del mercado de trabajo.

El enfoque teórico de la ética profesional permite comprender que, en la visión de Carr-Saunders y Wilson (1933), las tareas que realizan los profesionistas se conciben como la función social que les corresponde cumplir, puesto que establecen como fin o propósito prestar un servicio a la sociedad. La perspectiva filosófica de la ética profesional concibe este fin como el bien necesario e imprescindible para la vida social que debe proporcionar cada profesión. El sustento de dicho planteamiento es la visión de práctica elaborada por MacIntyre (2009), autor que comprende a este bien como el bien interno o intrínseco de la profesión debido al cual adquiere sentido. Es decir, las profesiones, mediante la prestación del servicio profesional, aportan a la sociedad el beneficio que les atañe y por ello son aceptadas y reconocidas socialmente.

MacIntyre (...) entiende por práctica una actividad social cooperativa que se caracteriza por tender a alcanzar unos bienes que son internos a ella misma y 


\section{Revista Iberoamericana \\ de las Ciencias Sociales y \\ Humanísticas}

ISSN: $2395-7972$

que ninguna otra puede proporcionar. Estos bienes son los que le dan sentido, constituyen la racionalidad que le es propia y, a la vez, le prestan legitimidad social. (...) Trasladando esta caracterización a las actividades profesionales, podríamos decir que el bien interno de la sanidad es el bien del paciente; el de la empresa, la satisfacción de las necesidades humanas con calidad, el de la docencia, la transmisión de la cultura y la formación de personas críticas (Cortina, 2006, p. 61).

Es de destacar que Carr-Saunders y Wilson (1933), al establecer que las profesiones se desarrollan con un fin o función social inherente, muestran la naturaleza social y moral de las profesiones modernas. La postura filosófica de la ética profesional, por su parte, al proclamar que este fin constituye el bien o la contribución que hacen las profesiones a la sociedad, devela que esta ética es intrínseca a estas, ya que el servicio que proporcionan involucra la responsabilidad y el compromiso moral de satisfacer las necesidades vitales de la sociedad (Feito, 2009, p. 129).

Para un autor como Fernández (2001), Carr-Saunders y Wilson (1933) reconocen esa sustancia de la ética profesional y lo recuperan en su visión de la ética del servicio profesional.

Para la década de los treinta, Carr-Saunders y Wilson (1933) señalaban que una ocupación alcanzaba el estatus de una profesión cuando un tipo de actividad no se ejerce más que mediante la adquisición de una formación controlada, la sumisión a reglas y normas de conducta entre los miembros y los no miembros, y la adhesión de una ética del servicio social (Fernández, 2001, p. 25).

Aquí cabe preguntar: ¿qué significa esta ética del servicio social?

En principio, es una es una ética autónoma, ya que es propia y exclusiva de las profesiones, que tiene como referente el servicio que prestan y no los principios ni valores religiosos que predominaron en la época precapitalista. El enfoque filosófico de la ética

profesional da cuenta del proceso que ésta fue experimentando para separarse del ámbito religioso hasta concebirse como una ética del servicio profesional. 


\section{Revista Iberoamericana \\ de las Ciencias Sociales y \\ Humanísticas}

ISSN: 2395 - 7972

Es en la Modernidad cuando las profesiones empiezan a emanciparse de la esfera religiosa y a fundamentarse en una ética autónoma. Como bien muestra Max Weber, la palabra alemana (Beruf) e inglesa (calling), que traducimos por profesión, tienen a la vez el sentido de vocación y de misión, y reciben el significado que ahora le damos sobre todo a partir de la reforma protestante. En efecto, son los reformadores los que, sin pretenderlo, sientan las bases para que pueda entenderse que la propia conducta moral consiste en sentir como un deber el cumplimiento de la tarea profesional en el mundo (Cortina, 2006, p. 57).

Así, la ética del servicio social muestra que en el ámbito de las profesiones se ha cancelado el concepto religioso por el que se comprendía el cumplimiento de las actividades profesionales como un deber religioso, y se sustituye por un deber u obligación moral mediante el cual responden al interés social. Este interés es de gran valor y alcance porque, al prestar un servicio a una persona que carece de los conocimientos y habilidades que tiene un profesional, no solo están contribuyendo a resolver sus necesidades particulares, sino que están aportando a una causa social de gran trascendencia: la sobrevivencia y el desarrollo de la sociedad.

De esta forma, aunque en la modernidad se rompe con el concepto religioso de la profesión, prevalece en el campo la convicción de que hay una tarea o misión particular en la sociedad y se asume como una obligación moral. Este deber involucra realizar las actividades profesionales con responsabilidad y desarrollarlas en función del interés social y no del provecho personal. Es decir, por ejemplo, el médico entiende que tiene como cometido preservar o restablecer la salud del paciente, el docente asume que es inherente a su profesión lograr la educación de los alumnos, y así con cada una de las profesiones modernas.

Para comprender el sentido de esta ética del servicio social es importante tomar en cuenta tanto el ángulo funcionalista desde el que se concibe a las profesiones como el contexto histórico marcado por el proceso acelerado de la industrialización. Esta visión funcionalista permite entender que la ética del servicio social se plantea en relación con la contribución que pueden hacer las profesiones para lograr el equilibrio y la estabilidad de la vida social y económica, lo que resulta relevante para impulsar y consolidar el capitalismo como modelo económico. Las profesiones pueden cumplir con esta función porque "heredan, mantienen y transmiten una tradición, engendran modos de vida, formas de pensar que las 


\section{Revista Iberoamericana \\ de las Ciencias Sociales y \\ Humanísticas}

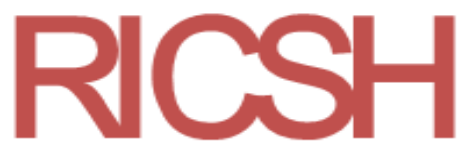

ISSN: $2395-7972$

convierten en centros de resistencia contra las fuerzas que amenazan una evolución pacífica" (Carr-Saunders y Wilson, 1933, citados en Rodríguez, 2008, p. 29).

En este marco, si bien Carr- Saunders y Wilson (1933) establecen que la tarea que realizan las profesiones tiene como fin proporcionar un servicio, la trascendencia de este se entiende como la contribución al equilibrio y avance de la sociedad de forma ordenada y estructurada. La postura funcionalista concibe a la sociedad como un todo articulado por partes interdependientes, las cuales cumplen un rol o función social para alcanzar la estabilidad que consideran necesaria para el funcionamiento grupal. Desde este enfoque, el rol o función social de las profesiones es contribuir al progreso y desarrollo de la sociedad capitalista.

El funcionalismo pretende construir una teoría del funcionamiento y de la génesis de los grupos profesionales. Su racionalidad no consiste en describir sus principales características en cuanto tales, sino en identificar cuáles son las funciones que cumplen en la sociedad (...). Las profesiones constituyen mediaciones entre las necesidades individuales y las necesidades funcionales de la sociedad y contribuyen a la regulación y el control que permite el buen funcionamiento de la sociedad (Tenti, 1989, p. 27).

\section{Ética profesional como códigos éticos}

Después de la Segunda Guerra Mundial, en la sociología de las profesiones sigue predominando el enfoque funcionalista, pero se experimenta un giro en su ámbito de análisis, pues las investigaciones ya no se centran en definir los atributos o características que distinguen a las profesiones, sino en el proceso de profesionalización entendido como las etapas o momentos que toda ocupación tiene que cumplir para alcanzar el estatus de profesión.

En este texto se recupera la visión de la profesionalización elaborada por Wilensky (citado en Dettmer, 2009) y Moore (citado en Machado, 1991) que ha sido considerada un referente clásico y obligado para abordar el estudio del debatido tema aquí en cuestión. El eje de análisis de este apartado es el modelo de Wilensky (1964) y se recuperan aspectos de la propuesta de Moore (citado en Machado, 1991) para presentar de manera más acabada este planteamiento funcionalista que predominó en el ámbito de la sociología de las profesiones 


\section{Revista Iberoamericana \\ de las Ciencias Sociales y \\ Humanísticas}

ISSN: 2395 - 7972

hasta los inicios de la década de los 70, cuando se hacen presentes otros enfoques como el neomarxista Larson (1989) y el neoweberiano (Freidson, 2003).

El modelo del proceso de profesionalización es resultado del siguiente estudio:

Wilensky en su ya famoso artículo de 1964 observó al analizar las fechas en que tuvieron lugar eventos formales - creación de primeras escuelas de formación y entrenamiento, primeras universidades, primeras asociaciones locales, primeras asociaciones nacionales, leyes estableciendo licenciaturas y otras credenciales y establecimiento de unos códigos éticos- que las profesiones norteamericanas seguían una secuencia evolutiva común. A partir de esta constatación construyó una narrativa para explicar este proceso (González, 1999, p. 32).

Se comprende, entonces, que este modelo se elaboró con base en las acciones que realizaron distintas ocupaciones norteamericanas y en diferentes momentos históricos para lograr el estatus de profesiones, a partir de las cuales se establece una serie de etapas propias del proceso de profesionalización.

Rodríguez y Guillén (1992) han situado a Wilensky (1964) en la escuela evolutiva de la sociología de las profesiones, cuyo planteamiento aquí se recupera a razón de que este modelo expresa una visión funcionalista de la realidad social, entendida como un proceso de evolución natural mediante el cual la sociedad va alcanzando mejores niveles de desarrollo, y en esa dinámica se inserta el proceso de profesionalización. Por ello, se concibe como una secuencia lineal por etapas, donde no caben conflictos ni fuerzas externas que impidan el tránsito "natural" de una ocupación a una profesión. Asimismo, este proceso conlleva a un tipo ideal de profesión, pues no todas las profesiones han seguido el orden o secuencia que presenta este modelo para alcanzar dicho estatus.

Para el enfoque crítico de la sociología de las profesiones (Freidson, 2003; Larson, 1989), este modelo de profesionalización muestra cómo es posible que, a través del cumplimiento de cada una de estas etapas, los grupos profesionales puedan consolidarse en agrupaciones económicas y sociales con prestigio y acceso al poder. Las etapas de este proceso constituyen la base para que las profesiones organizadas en un colectivo de tipo corporativo busquen el monopolio del conocimiento y del mercado de trabajo, así como la autonomía y la autorregulación moral. 


\section{Revista Iberoamericana \\ de las Ciencias Sociales y \\ Humanísticas}

ISSN: $2395-7972$

Siguiendo a Evetts (2003) y Hernández (2017), Larson en su obra The Rise of Professionalism realizó una crítica radical a esta visión funcionalista de las profesiones al establecer que el proceso de profesionalización constituye un proyecto profesional "professional project"- en palabras de Hernández (2017, p. 82) - Para esta última autora, dicho proceso estuvo perfilado a realizar acciones para conseguir el monopolio del mercado de los servicios profesionales y, al mismo tiempo, impulsar y lograr una movilidad ascendente para que las profesiones lograran un mayor y mejor estatus social tanto de manera individual como colectiva.

De acuerdo con Evetts (2003, p. 36), para Freidson (2003) el proceso de profesionalización no implicó la obtención del monopolio del mercado de servicios profesionales, sino el logro de nichos de mercado protegidos.

En relación con la ética profesional, tanto Wilensky (citado en Dettmer, 2009) como Moore (citado en Machado, 1991) reconocen como un componente de la profesionalización la elaboración de códigos éticos donde queda plasmada la visión funcionalista de la ética profesional. Es por ello por lo que resulta pertinente y necesario analizar estos códigos de manera articulada con el conjunto de componente que estructuran este modelo. En la siguiente tabla (1) se sintetizan y presentan los elementos que componen el modelo de profesionalización propuestos por Wilensky (citado por Dettmer, 2009) y Moore (citado por Machado, 1991). 
Tabla 1. Modelo de profesionalización

\begin{tabular}{|c|c|}
\hline nsky (1964) & Moore (1970) \\
\hline $\begin{array}{l}\text { 1) Que el trabajo se convierta en una } \\
\text { ocupación de tiempo completo. } \\
\text { 2) Establecimiento de una escuela o } \\
\text { universidad. } \\
\text { 3) Formación de una asociación } \\
\text { profesional. } \\
\text { 4) "La búsqueda de reconocimiento y el } \\
\text { apoyo legal para controlar el acceso y las } \\
\text { formas de ejercicio de la profesión". } \\
\text { 5) Formulación de un código de ética } \\
\text { formal. }\end{array}$ & $\begin{array}{l}\text { 1) Ocupación de tiempo integral. El } \\
\text { profesional obtiene sus ingresos para vivir } \\
\text { de la realización de la actividad profesional. } \\
\text { 2) Se caracterizan por tener "vocación". } \\
\text { 3) Poseen una organización y adoptan un } \\
\text { código de ética. } \\
\text { 4) Tienen un cuerpo de conocimientos } \\
\text { formal que se transmite en las universidades. } \\
\text { 5) Poseen orientación para el servicio, y } \\
\text { desarrollan una práctica social. } \\
\text { 6) Poseen autonomía y está presente el } \\
\text { corporativismo. }\end{array}$ \\
\hline
\end{tabular}

Fuente: Elaboración propia con base en Dettmer (2009) y Machado (1991)

\section{La profesión de tiempo completo}

Las profesiones, para alcanzar este estatus, demandan jornadas de tiempo completo. Al respecto, More (citado en Machado, 1991) establece como un signo que distingue a los profesionistas el hecho de que la práctica profesional constituye su principal fuente de ingresos y por ello su medio de vida. En este planteamiento, es posible reconocer la concepción de las profesiones elaborada por Max Weber (1969): "Es la actividad especializada y permanente de un hombre, que, normalmente, constituye para él una fuente de ingresos y, por tanto, un fundamento económico seguro de su existencia" (Cortina, 2000, p. 13).

Así, en esta etapa, la profesión se concibe como medio de vida y se establece este atributo para distinguirla de otros grupos sociales, como son los hombres de negocios que poseen riqueza y bienes materiales, así como los aristócratas que heredan dinero y propiedades que constituyen su sustento económico. En otras palabras, los profesionistas obtienen sus ingresos a través del ejercicio profesional, el cual se considera una retribución bien ganada y fruto de sus competencias científicas adquiridas mediante un largo proceso de formación universitaria. 


\section{Revista Iberoamericana \\ de las Ciencias Sociales y \\ Humanísticas}

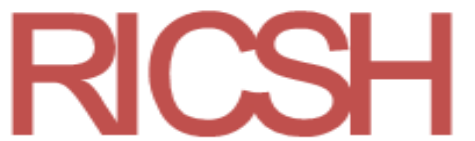

ISSN: $2395-7972$

Cortina (2000) ofrece una visión filosófica de las profesiones que destaca porque establece que, en términos sociales y morales, estas no se limitan a ser un medio de vida: cumplen una función social que les permite ser aceptadas y reconocidas por la sociedad.

Por eso, la profesión es social y moralmente mucho más que un medio individual de procurarse el sustento. Podríamos caracterizarla como una actividad social cooperativa, cuya meta interna consiste en proporcionar a la sociedad un bien específico e indispensable para su supervivencia como sociedad humana para lo cual se precisa el concurso de la comunidad de profesionales que como tales se identifican ante la sociedad (Cortina, 2000, p. 15).

La disposición de ejercer durante jornadas de tiempo completo se conserva actualmente como un rasgo que distingue a las profesiones modernas. Por ejemplo, aquellos profesionales que forman parte de los recursos humanos de una institución u organización de carácter privado o público que generalmente tienen plazas de tiempo completo avaladas en la función que cumplen o el servicio que proporcionan. Asimismo, el ejercicio profesional es el principal medio de vida tanto para los profesionistas liberales como para aquellas personas que obtienen sus ingresos ejerciendo en instituciones y organizaciones.

\section{Profesiones y universidad}

La segunda etapa del proceso de profesionalización sitúa a las universidades como las instituciones especializadas en la formación de los futuros miembros de este grupo, ya que les proporcionan los conocimientos y habilidades requeridas para realizar la práctica

profesional. Así, se establece que las universidades son las instituciones reconocidas y aceptadas, tanto por las profesiones como por la sociedad como las entidades legítimas, para certificar mediante un título las capacidades adquiridas que, a su vez, respaldan la realización del ejercicio profesional.

González (1999, p. 63) precisa que en la visión de Larson las profesiones establecieron una relación estructural con las universidades con el interés de que su conocimiento científico y técnico se institucionalizara para que formaran a los futuros profesionistas en un tipo o modelo de profesión con el fin de generar y consolidar un mercado de servicios profesionales. En sintonía con este argumento, Dettmer (2009) señala lo siguiente:

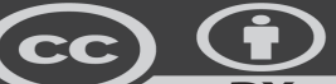




\section{Revista Iberoamericana \\ de las Ciencias Sociales y \\ Humanísticas}

ISSN: $2395-7972$

Al analizar los procesos clásicos de profesionalización — surgidos durante la fase del capitalismo competitivo - Larson constata que en el logro de estos objetivos la universidad jugó un papel clave en la configuración de las profesiones tradicionales (medicina, derecho y arquitectura) al unir dos trayectorias hasta entonces independientes: la primera, derivada de la existencia de cuerpos específicos de conocimiento técnico-teórico; y la segunda, marcada por la constitución de mercados potenciales o efectivos, para servicios o trabajos que requerían del dominio de ciertas habilidades. No obstante, para unificar en la práctica ambas trayectorias fue necesario que los grupos profesionales existentes transfirieran a la universidad el monopolio sobre la formación de productores u oferentes de servicios profesionales (Dettmer, 2009, p. 20).

Así, para este enfoque las universidades no solo fueron necesarias para generar y posicionar a las profesiones en un mercado de servicios profesionales, sino también fueron un mecanismo que impulsó su estrategia de movilidad ascendente para alcanzar mejor estatus social, a partir de un prestigio respaldado por los títulos y certificados universitarios.

En la actualidad estas instituciones de educación superior han sido reconocidas y avaladas social y jurídicamente como las entidades donde se forma a los futuros profesionistas que requiere la sociedad. Esta es la función social que cumplen, la cual no responde a los intereses de ningún grupo profesional. Sin embargo, este modelo de profesionalización contribuyó a consolidar como un atributo propio de las profesiones modernas contar con una formación avalada por un título expedido por una institución educativa superior que certifica y respalda jurídicamente que el profesionista está capacitado para ejercer.

\section{Profesiones y asociaciones profesionales}

La etapa tres del proceso de profesionalización comprende:

La creación de asociaciones profesionales que consoliden el espíritu de la profesión, los criterios de selección y estándares de calidad de los nuevos miembros, y definan las tareas profesionales esenciales con objeto de diferenciarse de ocupaciones similares poco profesionalizadas (Dettmer, 2009, p.16). 


\section{Revista Iberoamericana \\ de las Ciencias Sociales y \\ Humanísticas}

ISSN: 2395 - 7972

Así, las asociaciones profesionales se conciben como una forma de organización de los grupos profesionales perfilada a cohesionar y a defender sus intereses económicos y sociales. No solo tienen como propósito agrupar y dotar de identidad a las profesiones, sino ante todo contribuir a conquistar ese nicho de trabajo protegido al que alude Freidson (2003). Por ello, se establece como prioridad de estas organizaciones delimitar de manera conjunta las tareas o funciones que cumplen en la sociedad como grupo profesional, lo cual les permite diferenciarse de otras ocupaciones y profesiones que tienen una función o tarea semejante, a la vez que enfrentan la competencia con otros grupos profesionales que también pretenden realizar esa tarea que consideran propia.

Asimismo, los miembros de dichas asociaciones establecen sus propios criterios de selección y las medidas de calidad para ingresar a este tipo de organismo profesional, buscando con ello cerrar el mercado de servicios profesionales a otros profesionistas que no formen parte de este colectivo.

Esto lo argumenta Evetts (2003) al referirse al análisis crítico realizado por Larson del proceso de profesionalización:

Todo esto vino a entenderse como el análisis de los procesos históricos y contemporáneos mediante los que un grupo ocupacional fue capaz de cerrar el mercado (a los no formados, no cualificados o sin credenciales) consiguiendo así un salario y una posición de estatus privilegiados para sus profesiones (Evetts, 2003, p. 35).

Cortina (2000) no descalifica ni descarta a estas formas de organización de las profesiones modernas porque considera que pueden contribuir a la moralización de la sociedad siempre y cuando eliminen al corporativismo. El argumento de esta autora es el siguiente:

Decíamos en el primer apartado que cualquier sociedad que desee evitar orientarse únicamente por dos referentes, por el Estado y por el mercado, necesita potenciar las asociaciones intermedias (...). Esta es, obviamente, una de las razones por las que en nuestro momento determinados grupos progresistas procuran un fortalecimiento de la sociedad civil, especialmente de aquellas asociaciones de la sociedad civil y del marco de opinión pública que pueden ser fuente de moralización social. Entre las asociaciones voluntarias se encuentran los colegios profesionales (Cortina, 2000, p. 23). 


\section{Revista Iberoamericana \\ de las Ciencias Sociales y \\ Humanísticas}

ISSN: $2395-7972$

Aunque este modelo de profesionalización estuvo marcado por el corporativismo, no puede negarse que las asociaciones profesionales son las organizaciones que anteceden e impulsan a los actuales colegios profesionales. En esta medida, es un rasgo propio de las profesiones modernas que prevalece como un signo de estatus profesional o como mecanismo de regulación, puesto que en varios países se exige que los profesionales formen parte de una asociación o un colegio como requisito para ejercer.

\section{Profesiones y el Estado}

Las asociaciones profesionales fueron una sólida base para que los grupos profesionales realizaran acciones ante el Estado con el propósito de buscar la protección legal, para delimitar y controlar el mercado de trabajo donde realizaban su práctica profesional. Asimismo, estas asociaciones contribuyeron a lograr que la sociedad valorara la importancia del servicio profesional que prestaban sus integrantes. El papel que desempeñaron estas asociaciones para que los grupos profesionales pidieran la garantía legal es el siguiente:

La formación de una asociación profesional es parte de un proceso continuo para establecer y definir la función ocupacional tanto para establecer modelos y normas dentro de la ocupación como para dirigir sus relaciones con otros grupos competitivos. Estas proporcionan la base de la cuarta etapa, en la cual la ocupación trata de conseguir el reconocimiento público y el apoyo legal para su control de acceso a ella y las formas en que se debe ejercer. El apoyo legal generalmente toma forma de restricciones en el uso del nombre profesional, aunque en algunos casos la restricción directa e indirecta se ha situado en la realización de la función profesional (Elliott, 1875, p. 120).

De acuerdo con Hernández (2017, p 82), para Larson la estrategia del proyecto profesional (profesionalización) es conseguir, en primer término, el monopolio del conocimiento, a saber, el reconocimiento legal y social de que solo las profesiones cuentan con los conocimientos científicos, así como las competencias y habilidades técnicas para proporcionar los servicios profesionales que necesita la sociedad. El logro de este privilegio es importante tanto para obtener el control de los mercados de servicios profesionales como para alcanzar la autonomía profesional. 


\section{Revista Iberoamericana \\ de las Ciencias Sociales y \\ Humanísticas}

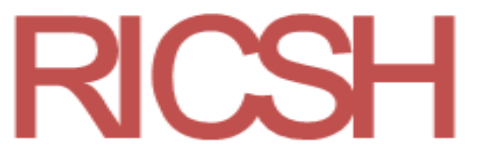

ISSN: 2395 - 7972

Para González (1999), el enfoque crítico de la sociología de las profesiones da cuenta del papel del Estado en este proceso de profesionalización:

Partiendo de diferentes intereses, Sarfatti Larson llega a resultados que coinciden en bastantes aspectos con Freidson. Para ambos, el Estado asegura las condiciones de la profesionalización y es a su vez el que facilita, condiciona y asegura la autonomía profesional (p. 71).

Esta etapa del modelo de profesionalización muestra que los grupos profesionales de las décadas de los 60 y 70 tenían el corporativismo como un rasgo que los distinguía, que se manifestaba también en las acciones políticas que realizaban ante el Estado para concretar sus intereses económicos y sociales. Esto se explica por el contexto económico y social de esas décadas marcadas por el desarrollo del capitalismo competitivo.

\section{Profesiones y códigos éticos}

Los códigos éticos constituyen la etapa cinco del proceso de profesionalización y tienen las siguientes funciones: "Eliminar a los no cualificados y los inescrupulosos, de forma tal que se reduzca la competencia interna, se proteja a los clientes y se ponga énfasis en el ideal de servicios" (Wilensky, 1964, citado en Finkel, 1999, p. 201).

Esta visión de los códigos éticos muestra el cambio y la evolución que tiene la ética profesional en el marco de la concepción de las profesiones propia del funcionalismo. Como se ha señalado anteriormente, la concepción de las profesiones de Carr-Saunders y Wilson (1933) rompe con las ideas religiosas que permeaban la moral de las profesiones y antepone una ética de servicio perfilada a satisfacer las necesidades de la sociedad. Asimismo, esta ética se concibe y presenta como una ética autónoma, es decir, una propia y exclusiva de las profesiones. Con esta concepción de la ética profesional como una autónoma se afirman las bases para avanzar al siguiente paso: la autorregulación moral por parte de las mismas profesiones. En esta perspectiva, se entiende el planteamiento de un código ético como etapa del proceso de profesionalización.

De acuerdo con lo establecido por Wilensky (citado en Finkel, 1999), es posible señalar que los códigos éticos quedan sujetos a la lógica del "cierre del mercado de los servicios profesionales" al que alude Evetts (2003). Esto porque las normas morales son uno de los mecanismos para regular la competencia interna, excluyendo del grupo a los profesionistas que consideran que no están calificados para realizar el servicio profesional, 


\section{Revista Iberoamericana \\ de las Ciencias Sociales y \\ Humanísticas}

ISSN: $2395-7972$

así como aquellos que desde su valoración sean poco escrupulosos. Igualmente, se puede plantear que, como parte de la estrategia de movilidad social ascendente, prevalece en estos códigos éticos la prestación del servicio como un ideal o aspiración por alcanzar. Lo anterior es importante para las profesiones porque les permite preservar el carácter altruista de sus servicios mostrando al Estado y a la sociedad que no buscan satisfacer sus intereses económicos y sociales sino los de la sociedad.

Así, mientras que en la visión de las profesiones de Carr-Saunders y Wilson (1933) la ética del servicio se enfoca a satisfacer las necesidades de la sociedad, en el modelo de Wilensky (1964) los códigos éticos forman parte del proyecto profesional para conseguir el reconocimiento y la legitimidad social por parte del Estado y de la sociedad revistiendo al servicio profesional de un aura altruista. Este argumento se sostiene en el planteamiento de Hortal (1993), quien señala lo siguiente: “El código deontológico de un colectivo profesional es un instrumento más de consolidación de las aspiraciones de dicho colectivo a la estimación social y el status profesional pleno" (p. 211).

La presencia de los códigos tiene otra vertiente referida a la autorregulación moral que proponen los grupos profesionales a cambio del reconocimiento y legitimidad que les otorgue la sociedad. Los códigos éticos se presentan como el mecanismo que garantizan a la sociedad que el propio grupo profesional es capaz de vigilar y sancionar a sus miembros, en caso de que hagan un mal uso de las capacidades profesionales o tengan una práctica profesional poco o nada ética con los clientes o usuarios de los servicios profesionales.

En el marco de la perspectiva filosófica de la ética profesional, Hortal (2000) analiza de manera crítica los planteamientos elaborados por esta vertiente funcionalista. Para este autor, el conjunto de etapas que comprende el profesionalismo, incluyendo los códigos éticos, dan cuenta del "dentrismo", entendido como el proceso mediante el cual las profesiones modernas se autodefinen al establecer sus atributos y funciones de acuerdo con sus propios criterios sin tomar en cuenta a la sociedad en general ni a los usuarios de los servicios profesionales en particular. El término dentrismo lo recobra de J. Martín Moreno y A. de Miguel y se manifiesta de la siguiente forma: 


\section{Revista Iberoamericana \\ de las Ciencias Sociales y \\ Humanísticas}

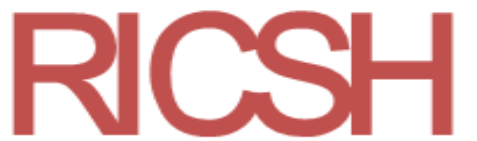

ISSN: $2395-7972$

Si se atendiese solo a las voces de los profesionales, a lo que ellos dicen de sí mismos, la esencia de su profesión consiste en el servicio desinteresado a la humanidad en el aspecto correspondiente de su funcionalidad específica. (...) Los privilegios de que goza no son sino elementos necesarios para mejor poder ejercer su profesión en beneficio de los clientes y usuarios, etc. (...) Pero en la institucionalización ineludible a que está sometida toda actividad social relevante y recurrente no todo responde exclusiva ni primordialmente a las necesidades del buen ejercicio profesional, también y mucho más a los intereses de quienes prestan este servicio. Si ellos son los únicos que entienden de eso, ellos tienen que ser también los únicos que pueden enjuiciar esas actividades. Con ello se crea la jurisdicción especial del colectivo profesional en régimen de monopolio (...). A los clientes y a las autoridades públicas solo les ofrecen garantías éticas y autocontrol profesional. Por eso se llega a afirmar que los códigos de ética profesional no son más que cortinas de humo para enmascarar intereses económicos y poder social (Hortal, 2000, pp. 4748).

Así, en esta visión del proceso de profesionalización, los códigos éticos forman parte de la estrategia de perseguir y defender el monopolio del mercado de los servicios profesionales en la medida en que avalan y respaldan en términos morales que las profesiones no solo garantizan un servicio eficaz, sino también un servicio en beneficio de la sociedad. Con base en esto, es posible plantear que, en este modelo, los códigos éticos, más que una ética profesional, expresan la moral de un grupo de corte corporativo. Esta moral se comprende como las normas o deberes morales definidos por el mismo grupo para autorregularse y autocontrolarse a sí mismos en términos morales, sin interferencia de terceros (Estado, sociedad, clientes o usuarios). Desde la perspectiva de la ética profesional, esta moral constituye la expresión de la tesis separatista:

La idea en la tesis separatista es que cada profesión se define en función de sus fines y procedimientos y, por tanto, tienen sus propios criterios de valor y, con ellos, su justificación moral inherente. Más que la negación de todo tipo de moral, lo que se pretende con esta interpretación del principio es afirmar una moral diferente, que se ampara en el concepto del deber y el servicio a un 


\section{Revista Iberoamericana \\ de las Ciencias Sociales y \\ Humanísticas}

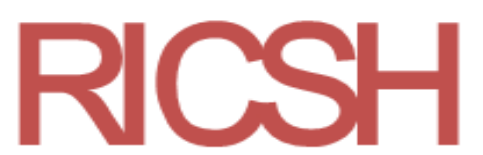

ISSN: 2395 - 7972

conjunto de valores predeterminados, y al que es necesario orientar todos nuestros actos (López de la Osa, 1994, p. 113).

Esta tesis separatista contribuye en gran medida a avalar el proyecto profesional porque su argumento permite situar a las profesiones modernas en términos morales y sociales por encima y al margen de la sociedad. Aquí cabe recuperar el término social closure (aislamiento social) elaborado por Larson (citado en Hernández, 2017, p. 82) para dar cuenta de que la estrategia del proyecto de profesionalización conlleva al aislamiento social de los grupos profesionales amparados en la autonomía profesional y moral.

La estrategia de aislamiento social obedece a la creación de un mercado profesional cerrado, un monopolio económico legal y un aislamiento sociocultural de una clase que detenta un saber legítimo sobre los que carecen de estos saberes y que lo precisan. Este saber legítimo queda institucionalizado en las universidades modernas y mediante la acción reguladora enlaza con la creación y mantenimiento preservado del mercado profesional. Este doble aislamiento hace imposible que la profesión sea controlada desde fuera convirtiéndose en peritos de su propia actuación (Hernández, 2017, p. 82).

Así, las profesiones cierran la posibilidad de que la sociedad intervenga en la valoración de su servicio bajo el argumento de que ellos poseen el conocimiento y las competencias científicas y, por lo tanto, están investidos de la autoridad para evaluar y calificar su ejercicio profesional. En esto sustentan su autonomía profesional y moral, puesto que, con su propia autorregulación moral, tampoco dan cabida a la sociedad para que pueda juzgar y calificar en términos morales la prestación del servicio profesional.

Para González (2006), la sociedad contemporánea actual ha experimentado un cambio de valores que le permite cuestionar el modelo clásico de las profesiones, que tenía como referentes el logro de privilegios, el estatus social y la autoridad, en gran medida porque los usuarios de los servicios profesionales exigen mayor participación en la prestación del servicio bajo la razón de que en ellos impacta directamente los resultados de este. En esto coincide Cortina (2000):

En efecto, las actividades profesionales se van desarrollando en el seno de sociedades cuya conciencia moral va evolucionando en el sentido de que las personas reclaman un mayor respeto a su autonomía, exigen que se respeten 


\section{Revista Iberoamericana \\ de las Ciencias Sociales y \\ Humanísticas}

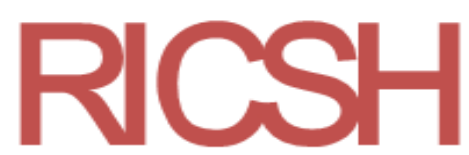

ISSN: 2395 - 7972

sus derechos, piden que se les deje participar en las decisiones que les afectan (p. 62).

En sintonía con este cambio de conciencia moral de la sociedad, las perspectivas teóricas actuales de la ética profesional han contribuido a fracturar la visión funcionalista, que situó a las profesiones como grupos privilegiados autónomos e independientes de la sociedad, porque para este enfoque filosófico la tarea actual de estas no reside tanto en la elaboración de normas morales (códigos éticos) que regulen a las profesiones, sino en lo puesto a continuación:

Diseñar de forma responsable cuáles son las buenas prácticas de la profesión y cuáles son las malas, teniendo en cuenta que se trata de una actividad social que cobra su sentido de perseguir una meta, la de proporcionar a la sociedad un bien específico (Cortina, 2000, p. 24).

En la realización de esta tarea, Martínez (2006) considera que tanto los usuarios de los servicios profesionales como la sociedad en general deben participar porque, al ser los directamente afectados por el servicio profesional, están en condiciones de aportar criterios, principios y valores que contribuyan a mejorar la calidad del servicio.

\section{Discusión}

La salvedad del análisis crítico que se desarrolló en este texto es que se limita a estudiar solo la visión funcionalista de la ética profesional elaborada por esta vertiente de la sociología de las profesiones, que constituye un campo de conocimiento donde están presentes otras corrientes y enfoques. Sin embargo, esta acotación se solventa porque la perspectiva funcionalista da cuenta de las acciones, prácticas, ideales, principios y valores que asumieron las profesiones para situarse y consolidarse en el mercado de servicios profesionales y en la sociedad. La postura funcionalista revela este momento clave en el desarrollo de las profesiones en general y de la ética profesional en particular.

Por ello, aquí se reconoce y rescata a algunos de los planteamientos elaborados por esta corriente funcionalista, ya que hace aportaciones importantes al definir en términos conceptuales qué es una profesión moderna y al establecer un conjunto de atributos y características que prevalecen en la actualidad como los criterios y parámetros para considerar a una ocupación con el estatus de profesión, tal y como: los profesionistas realizan una función social al proporcionar un servicio a la sociedad, el ejercicio profesional es su 


\section{Revista Iberoamericana \\ de las Ciencias Sociales y \\ Humanísticas}

ISSN: $2395-7972$

principal sustento económico, cuentan con una formación profesional adquirida en una universidad o institución de educación superior, realizan su práctica profesional respaldados por un título universitario que certifica y avala sus conocimientos y capacidades profesionales, se organizan en asociaciones o colegios mucho de los cuales tienen un código deontológico o ético.

Esta contribución es importante para definir y caracterizar a las profesiones. Sin embargo, la postura filosófica de la ética profesional permite entender que las profesiones modernas no se comprenden de manera integral si solo se conciben como grupos de individuos que cuentan con conocimientos científicos, y con capacidades y habilidades para realizar una práctica profesional, porque la esencia de estas es la ética profesional, que más que ser un atributo propio constituye su núcleo medular que posibilita su existencia y desarrollo. El estudio crítico que se expuso aquí, aunque reconoce esta estrechez que tiene la visión funcionalista de ética profesional, recupera los logros y el avance que tuvo esta ética como resultado del desarrollo de dicha conceptualización funcionalista. El primero es su emancipación del ámbito religioso; el segundo es consolidarse como una ética autónoma propia y particular de las profesiones; el tercero es asumirse como una ética de servicio, y el cuarto, concebir un código o conjunto de normas y deberes morales que actualmente se comprenden como los mínimos morales que están obligados a cumplir las profesiones modernas ante la sociedad contemporánea.

\section{Conclusiones}

El presente estudio crítico de la visión funcionalista de las profesiones es significativo porque centra el análisis en el periodo histórico en el que las profesiones modernas adquieren impulso y se consolidan a partir de las características y atributos que las definen, los cuales les permitió abrir un mercado de servicios profesionales y lograr el reconocimiento de la sociedad.

El eje de este estudio crítico fue la visión funcionalista de la ética profesional que permitió desarrollar cómo y por qué se establecen los atributos de las profesiones, la mayoría de los cuales se conservan en la actualidad, incluyendo a la ética profesional. La contribución central de este análisis es que expone las limitaciones que tiene esta concepción funcionalista para comprender el significado que tiene la ética profesional para las profesiones modernas, 


\section{Revista Iberoamericana \\ de las Ciencias Sociales y \\ Humanísticas}

ISSN: $2395-7972$

pero también revela el aporte que realizó para conocer la estructuración y el desarrollo de una ética particular de las profesiones en la modernidad.

La concepción funcionalista de la ética profesional fue analizada con base en los planteamientos de la perspectiva filosófica de la ética profesional y del enfoque crítico de la sociología de las profesiones. En este análisis ambas corrientes teóricas se complementaron para dar cuenta de los distintos aspectos y dimensiones que incidieron en la consolidación y progreso de las profesiones modernas y de la ética profesional.

La aportación del enfoque crítico de la sociología de las profesiones fue la crítica radical que realizó tanto a la concepción funcionalista de las profesiones como al modelo de profesionalización fundamentándose en los aspectos económicos, sociales y políticos que marcaron la dinámica de las profesiones y a la ética profesional en ese momento histórico. Así, esta postura muestra que las profesiones modernas no se pueden comprender y estudiar en la complejidad que encierran solo desde la óptica funcionalista, porque sus conceptualizaciones fueron producto de un contexto histórico específico.

La postura filosófica de la ética profesional permitió identificar las limitaciones que tiene esta visión en términos sociales y morales. Esta perspectiva no solo fue un apoyo para realizar una crítica a esta concepción funcionalista, sino que también aportó los fundamentos para comprender que el sentido o razón de ser de las profesiones modernas es la ética profesional. Con ello, la concepción de esta que ofrece dicho enfoque filosófico da cuenta del carácter social y moral de las profesiones modernas como propio o inherente a ellas. Asimismo, permitió comprender que el ethos de las profesiones que se expresa en la visión funcionalista no tiene cabida en la sociedad actual, donde existen otras condiciones económicas, sociales, políticas y culturales. 


\section{Revista Iberoamericana \\ de las Ciencias Sociales y \\ Humanísticas}

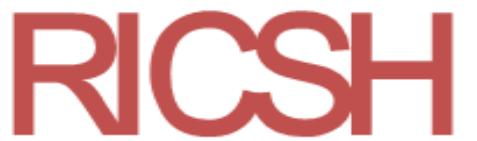

ISSN: $2395-7972$

\section{Referencias}

Aguayo, C. C. (2003). La profesión y la profesionalización: dilemas del conocimiento y del poder, algunas reflexiones para el trabajo social. Revista de Trabajo Social, (72), 97108. Recuperado de https://repositorio.uc.cl/handle/11534/6072.

Aguayo, C. C. (2006). Las profesiones modernas: dilemas del conocimiento y del poder, Santiago, Chile: Universidad Tecnológica Metropolitana. Recuperado de https.www.ts.ucr.ac.cr > binarios > libros > libros-000001.

Aguayo, C. C. (2007). Profesión y profesionalización: hacia una perspectiva ética de las competencias en trabajo social. Revista Tendencias \& Retos, (12), 107-117. Recuperado de www.ts.ucr.ac.cr > binarios > revistas > rev-co-tendencias-0012-07.

Aguayo, C. C. (2008). Ética profesional: una tensión constante entre la ética de la responsabilidad y de la convicción. Sociedade em Debate, Pelotas, 14(1), 81-88. Recuperado https://pdfs.semanticscholar.org/3acd/f046109099237eaf72d0334cca341f30a44e.pd f.

Carr-Saunders, A. M and Wilson, P.A (1933). The professions. Oxford, England: Clarendon Press.

Cortina, A. (2000). Presentación. El sentido de las profesiones. En A. Cortina y J. Conill (dirs.), 10 palabras clave en ética de las profesiones (pp. 13-28). Navarra, España: Verbo Divino.

Cortina, A. (2006). Universalizar la aristocracia: Por una ética de las profesiones. Revista Cultural de Santander, (1), 54-65. Recuperado de https://www.uis.edu.co/webUIS/es/mediosComunicacion/revistaSantander/revista1/ universalizarAristocracia.pdf.

Dettmer, J. (2009). La sociología de las profesiones: un estado del arte. En Alejandre, G. Pineda, J. y Rodríguez, R. (coords.), Sociología de las ocupaciones profesionales. Los procesos de institucionalización (pp. 13-26). Ciudad de México, México: Universidad Autónoma del Estado de México y Ediciones Eón.

Elliott, P. (1975). Sociología de las profesiones. Madrid, España: Tecnos.

Evetts, J. (2003). Sociología de los grupos profesionales: historia, conceptos, teoría. En Sánchez, M., Sáez, J. y Svensson, L. (coords), Sociología de las profesiones, pasado, presente y futuro (pp. 29-48). Murcia, España: Diego Marín, Librero-Editor. 


\section{Revista Iberoamericana \\ de las Ciencias Sociales y \\ Humanísticas}

ISSN: $2395-7972$

Fernández, P. J. A (2001). Elementos que consolidan al concepto profesión. Notas para su reflexión. Revista Electrónica de Investigación Educativa, 3(1). Recuperado de redie.uabs.mx $>$ redie $>$ article $>$ view

Feito, G. L. (2009). Ética y enfermería. Madrid, España: San Pablo, Universidad Pontificia Comillas.

Finkel, M. L. (1999). ¿Qué es un profesional?, Las principales conceptualizaciones de la Sociología de las Profesiones. En Castillo, C. A. (coord.), Economía, organización y trabajo. Un enfoque sociológico (pp. 197-228) España: Ed. Pirámide.

Finkel, M. L. (2015). La sociología de las profesiones: legados y perspectiva. (tesis doctoral). Universidad Complutense de Madrid, Madrid. Recuperado de https://eprints.ucm.es/37718/1/T37235.pdf.

Freidson, E. (2003). El alma del profesionalismo. En Sánchez, M., Sáez, J. y Svensson, L. (coords.), Sociología de las profesiones, pasado, presente y futuro (pp. 67-92). Murcia, España: Diego Marín, Librero-Editor.

González, L. R. (1999). Las profesiones: entre la vocación y el interés corporativo. Fundamentos para su estudio. Madrid, España: Editorial Catriel.

González, R. A. G. (2006). Bioética: ¿Se puede hablar de una ética profesional sanitaria?, Ágora, 25(1), 135-167. Recuperado de https://minerva.usc.es/xmlui/bitstream/handle/10347/1305/06.Gonzalez.pdf?sequen ce $=1$.

Hartwell, R. M. (1986). La moralidad del capitalismo. Revista Libertas, (4), 1-9. Recuperado de http://www.eseade.edu.ar/files/Libertas/46_1_Hartwell.pdf.

Hernández, L. A. (2017). El proceso de desprofesionalización del trabajo social en España (1980-2015): Déficit, riesgos y potencialidades. (tesis doctoral). Universidad Nacional de Educación a Distancia. Recuperado de http://espacio.uned.es/fez/view/tesisuned:ED-Pg-DeryCSoc-Lahernandez.

Hortal, A. A. (1993). Ética de las profesiones. Diálogos Filosóficos, (26).

Hortal, A. A. (2002). Ética general de las profesiones. Bilbao, España: Desclée De Brouwer.

Ibarra, R. G. (2015). Ética profesional y cívica para la formación universitaria. Revista Boletín Redipe, 4(7). Recuperado de http://revista.redipe.org/index.php/1/article/view/372. 


\section{Revista Iberoamericana \\ de las Ciencias Sociales y \\ Humanísticas}

ISSN: $2395-7972$

Larson, S. M. (1989). Acerca de los expertos y los profesionales o la imposibilidad de haberlo dicho todo. Revista de Educación, (Extra-1), 201-237. Recuperado de https://www.mecd.gob.es/dctm/revista-de-educacion/articulosre1990/re199007.pdf? documentId=0901e $72 \mathrm{~b} 8136908 \mathrm{c}$.

López de la Osa, J. R. (1994). La moral profesional: La corporativización, en el ejercicio de la profesión. En Hernández, J. L. y Hortal, A. (comps.), Ética de las profesiones (pp. 109-119). Madrid, España: Departamento de Publicaciones de la Universidad Pontificia Comillas.

MacIntyre, A. (2009). Tras la virtud. Barcelona, España: Editorial Crítica.

Machado, H. M. (1991). Sociología de las profesiones: un nuevo enfoque. Educación Médica y Salud, 25(1), 28-36.

Martínez, N. E. (2006). Ética de la profesión: proyecto personal y compromiso de ciudadanía, Veritas, Vol I, No 1, pp 121-139 Recuperado en: http://www.emiliomartinez. net/ pdf/Etica_Profesion.pdf

Rodríguez, Á. N. (2008). Manual de sociología de las profesione. Barcelona, España: Universitat de Barcelona.

Rodríguez, J. A. y Guillén, F. M. (1992). Organizaciones y profesiones en la sociedad contemporánea. Reis: Revista Española de Investigaciones Sociológicas, (59), 9-18. Recuperado de http://www.reis.cis.es/REIS/PDF/REIS_059_03.pdf.

Tenti, E. (1989). Elementos de teoría y análisis histórico. En Gómez, V. y Tenti, E., Universidad y profesiones. Crisis y alternativas (pp. 14-36). Buenos Aires, Argentina: Miño y Dávila Editores.

Wilensky, H. L. (1964). The professionalization of Everyone? American Journal of Sociology, 70(2). 